\title{
JUSTIÇA SOCIOAMBIENTAL E PROCESSO DE URBANIZAÇÃO DAS CIDADES ${ }^{1}$
}

\author{
SOCIO-ENVIRONMENTAL JUSTICE AND CITY URBANIZATION PROCESS
}

\author{
Magno Federici Gomes ${ }^{2}$ \\ Wallace Silva Pinto ${ }^{3}$
}

\begin{abstract}
RESUMO: A industrialização é, sem dúvida, o ponto de partida para a discussão dos problemas urbanos a partir de seus reflexos nos centros urbanos. A criação de postos de trabalho e o aumento de investimentos em transportes impulsionaram o comércio e estimularam a migração do campo para as cidades produzindo diversos problemas sociais. Este artigo de cunho teórico documental utiliza-se de doutrina, e leis e se propõe justificar e avaliar os instrumentos de aplicação para se conseguir uma cidade mais equitativa através da justa distribuição dos encargos e benefícios decorrentes do processo de urbanização. Verificou-se a importância da participação popular na elaboração das leis para a efetivação do planejamento urbano voltado para a redução dos problemas sociais e privilégios a determinados grupos. Conclui-se que apesar de o Estado possuir um conjunto de leis de controle do uso e ocupação do solo, na prática, os resultados de sua aplicação não são efetivos e para alcançar uma cidade mais igualitária deve lançar mão de instrumentos capazes de inibir a especulação imobiliária, possibilitar a recuperação da mais valia dos investimentos públicos de modo a privilegiar os direitos coletivos.
\end{abstract}

Palavras-chave: Industrialização, Urbanização, justiça social, igualdade.

\footnotetext{
${ }^{1}$ Trabalho financiado pelo Edital no 05/2016 (Projeto no FIP 2016/11173-S2) do FIP/PUC MINAS, resultante dos Grupos de Pesquisas (CNPQ): Regulação Ambiental da Atividade Econômica Sustentável (REGA), NEGESP, Metamorfose Jurídica e CEDIS (FCT-PT).

2 Estágio Pós-doutoral em Direito Público e Educação pela Universidade Nova de Lisboa-Portugal (Bolsa CAPES/BEX 3642/07-0). Estágios Pós-doutorais em Direito Civil e Processual Civil, Doutor em Direito e Mestre em Direito Processual, pela Universidad de Deusto-Espanha (Bolsa da Cátedra UNESCO e do Gobierno VascoEspanha). Mestre em Educação pela PUC Minas. Professor do Doutorado e Mestrado Acadêmico em Direito Ambiental e Desenvolvimento Sustentável na Escola Superior Dom Helder Câmara. Professor Adjunto da PUC Minas e Professor Titular licenciado da Faculdade de Direito Arnaldo Janssen. Advogado Sócio do Escritório Moraes \& Federici Advocacia Associada. Líder do Grupo de Pesquisa: Regulação Ambiental da Atividade Econômica Sustentável (REGA)/CNPQ-BRA e integrante dos grupos: Centro de Investigação \& Desenvolvimento sobre Direito e Sociedade (CEDIS)/FCT-PT, Núcleo de Estudos sobre Gestão de Políticas Públicas (NEGESP)/CNPQ-BRA e Metamorfose Jurídica/CNPQ-BRA. ORCID: http://orcid.org/0000-0002-47115310. Currículo Lattes: http://lattes.cnpq.br/1638327245727283. E-mail: federici@pucminas.br

${ }^{3}$ Estágio Pós-doutoral em Direito Público e Educação pela Universidade Nova de Lisboa-Portugal (Bolsa CAPES/BEX 3642/07-0). Estágios Pós-doutorais em Direito Civil e Processual Civil, Doutor em Direito e Mestre em Direito Processual, pela Universidad de Deusto-Espanha (Bolsa da Cátedra UNESCO e do Gobierno VascoEspanha). Mestre em Educação pela PUC Minas. Professor do Doutorado e Mestrado Acadêmico em Direito Ambiental e Desenvolvimento Sustentável na Escola Superior Dom Helder Câmara. Professor Adjunto da PUC Minas e Professor Titular licenciado da Faculdade de Direito Arnaldo Janssen. Advogado Sócio do Escritório Moraes \& Federici Advocacia Associada. Líder do Grupo de Pesquisa: Regulação Ambiental da Atividade Econômica Sustentável (REGA)/CNPQ-BRA e integrante dos grupos: Centro de Investigação \& Desenvolvimento sobre Direito e Sociedade (CEDIS)/FCT-PT, Núcleo de Estudos sobre Gestão de Políticas Públicas (NEGESP)/CNPQ-BRA e Metamorfose Jurídica/CNPQ-BRA. ORCID: http://orcid.org/0000-0002-47115310. Currículo Lattes: http://lattes.cnpq.br/1638327245727283. E-mail: federici@pucminas.br
} 
ABSTRACT: Industrialization is without a doubt the starting point for the discussion of urban problems from their reflections in urban centers. Job creations and increased investment in transport pushed up the trade and stimulated migration from the countryside to the cities producing a variety of social problems. This theoretical documentary article uses doctrine, jurisprudence and laws and proposes to evaluate the instruments of application to achieve a more equitable city through the fair distribution of the burdens and benefits resulting from the urbanization process. It was verified the importance of popular participation in the elaboration of laws for the effective implementation of urban planning aimed at reducing social problems and privileges to certain groups. It is concluded that although the State has a set of laws to control land use and occupation, in practice, the results of its application are not effective and to reach a more egalitarian city must resort to instruments capable of inhibiting speculation real estate, make it possible to recover the added value of public investments in order to privilege collective rights.

Keywords: Industrialization, Urbanization, social justice, equality.

SUMÁRIO: Introdução. 1 Evolução das cidades. 2 Desenvolvimento dos centros urbanos. 3 Planejamento urbano e sustentabilidade. 4 Usufruto equitativo da cidade e o princípio da justa distribuição dos encargos e benefícios. Considerações finais. Referências.

\section{INTRODUÇÃO}

O processo de industrialização é, sem embargo, o principal instrumento de transformação das sociedades, mas traz diversos problemas referentes ao desenvolvimento e crescimento das cidades que impactam diretamente na vida dos cidadãos. O tema em questão é de grande relevância social ao colocar em discussão a possibilidade de adoção de medidas pelo Estado para a distribuição dos encargos e benefícios na produção de uma cidade mais justa e igualitária.

Apesar da evolução na produção de leis capazes de gerar mais justiça social, as cidades ainda apresentam violentos contrastes entre ricos e pobres, principalmente pela gigantesca exclusão social marcada por uma nova realidade que prioriza o valor de uso ${ }^{4}$ através da valorização do solo urbano. Adota-se como hipótese que se o processo de crescimento e urbanização das cidades forem bem planejados, com prioridade da efetiva participação popular e sem privilégios a certos grupos haverá condições de se alcançar o usufruto equitativo e a justa distribuição dos encargos e benefícios desse processo.

\footnotetext{
${ }^{4}$ Conforme explica Kaap, existia uma disputa dos capitais por localização e pelo valor de uso das cidades, a indústria imobiliária e as operações especulativas continuam muito mais determinantes na produção do espaço urbano do que qualquer participação popular nas decisões do Estado ou qualquer função social da propriedade (KAPP, 2012, p. 467)
} 
O presente trabalho de cunho teórico documental utiliza-se de doutrina, posicionamentos jurisprudenciais e leis para discutir formas de evitar que os investimentos públicos na cidade tenham os benefícios de sua implantação privatizados por uma minoria e, com isso, promover o acesso igualitário aos benefícios da cidade com a participação democrática nas decisões de modo a garantir o usufruto igualitário da cidade e a justa distribuição dos seus encargos e benefícios.

O trabalho tem como marco teórico a obra de Lefebvre (2001), que trata de temas de grande interesse acadêmico e social, abordando assuntos como os impactos da industrialização na urbanização, a importância da participação popular nas decisões e o direito à cidade na perspectiva dada pelo autor em que esse direito se manifesta como a forma superior dos direitos: direito à liberdade, à individualização na socialização, ao habitat e ao habitar, mas principalmente como forma de alcançar uma cidade igualitária e justa.

A industrialização impõe mudanças no desenho e na arquitetura das cidades que podem ser observadas ao se comparar os períodos pré e pós o seu início. Antes da industrialização, as cidades orientais estavam ligadas ao modo de produção asiático, as cidades romanas à posse de escravos e as cidades medievais inseridas nas relações feudais. Com a chegada da indústria e o nascimento do capitalismo as cidades se desenvolveram, acumularam riquezas, adotaram um sistema de produção distante da agricultura e utilizaram mão de obra camponesa, dando início a centros de política e vida social.

A concentração de pessoas em torno de um local onde se buscava trabalho e acumulação de riquezas fez surgir os centros urbanos e com eles a vida em comunidade e problemas como os contrastes entre riqueza e pobreza e conflitos entre os poderosos e os oprimidos. As cidades crescem rapidamente e o Estado, mesmo com amplo e rigoroso aparato de leis para controlar a produção do espaço urbano, não consegue suprir na mesma velocidade as necessidades de um planejamento urbano que evite o surgimento dos contrastes sociais, principalmente devido ao crescimento desordenado.

O forte crescimento da economia e o aumento dos postos de trabalho nos centros urbanos motivaram a migração do campo para a cidade causando aumento por demanda de moradia e consequente aglomeração de pessoas vivendo em subúrbios devido a falta de infraestrutura das cidades para receber esse contingente de pessoas. Essa situação fomentava ainda mais a necessidade de um planejamento urbano pensado de modo sustentável com o objetivo de garantir o mínimo de qualidade de vida para as gerações presentes e futuras. 
Com o objetivo de impedir que uma minoria da população receba os benefícios dos investimentos públicos, o Estado deve adotar o planejamento urbano que contemple medidas para a recuperação e distribuição dos investimentos públicos ainda que interfiram em direitos individuais e de determinados grupos sociais, mas que ao final contemple a maioria da população via privilégio dos direitos coletivos.

É inerente ao processo de desenvolvimento e urbanização a necessidade de investimentos públicos na cidade de modo a fornecer aos cidadãos equipamentos públicos como praças, escolas e saúde, garantindo assim o acesso igualitário aos benefícios da cidade. Ocorre que o investimento feito em um setor da cidade leva à valorização imobiliária sem que o proprietário tenha feito qualquer esforço implicando em ganho de benefícios para uma minoria em detrimento da maior parcela da população.

Ocorre, portanto, a privatização dos benefícios dos investimentos públicos devendo o Estado adotar políticas que garantam um planejamento urbanístico bem elaborado, a efetivação da função social, observando as previsões legais existentes de modo a conseguir uma cidade igualitária e com justiça social.

Pretende-se, portanto, discutir os problemas enfrentados pelas cidades devido ao processo de industrialização e de urbanização sem planejamento urbanístico participativo com foco no social capaz de garantir a igual distribuição dos benefícios e dos ônus que decorrem do processo da urbanização. Assim, a segunda e terceira partes deste trabalho tratam da evolução das cidades e do desenvolvimento dos centros urbanos, passando a discutir sobre o planejamento urbano e sustentabilidade como garantia de uma cidade com menor exclusão social na quarta parte e, por fim, a possibilidade de o Estado adotar medidas que garantam o usufruto equitativo da cidade e a justa distribuição dos encargos e benefícios do processo de urbanização sendo discutida na quinta parte do trabalho.

\section{EVOLUÇÃO DAS CIDADES}

A descoberta pelo homem de técnicas de fabricação de pequenas ferramentas, controle do fogo e técnicas rudimentares de cultivo tornaram possível o abandono da forma de vida nômade, criando condições para o surgimento e crescimento das cidades, conforme descreve Maluf (2010):

Nos tempos primitivos, no início do paleolítico, os homens levavam uma vida bastante semelhante à dos outros animais. Viviam em bandos, coletores de 
alimentos e restos de animais encontrados pelo caminho, ou seja, retiravam o seu sustento da natureza. Careciam de instrumentos e armas necessários à vida e à sua proteção, o que justificaria o seu nomadismo, pois quando o alimento de determinada região se extinguia era premente a necessidade de ir procurá-lo em outro lugar (MALUF, 2010, p. 9).

Segundo Costa, o aumento da população, o avanço em diversas áreas e o excedente de produção obrigou os feudos a buscarem outras formas de comercializar seus produtos expandindo os horizontes de comércio. Com o fim das invasões bárbaras houve um grande período de estabilidade favorecendo o surgimento dos burgos, pequenas aglomerações que mais tardes estruturaram-se em cidades, assim descrito por Costa (2013):

O fim das invasões, a estabilidade e as condições produtivas agiram sobre essa sociedade. Interessante notar que começaram-se a se estruturar vilas (burgos) e muitas destas conquistaram ou compraram sua autonomia, passando a funcionar como novo centro em torno do qual gravitou aquela nova sociedade em construção. Era um pré-capitalismo, uma nova classe social começou a ser formada e, em pouco tempo, produzir as condições para que acontecesse uma centralização político-administrativa, quando então a nobreza feudal decadente submeteu-se a um poder centralizado na figura do rei. Este, dispondo de recursos que cobrava dos habitantes dos burgos, mantinha exércitos permanentes e, desta forma, não dependia mais dos senhores feudais que antes protegiam, às suas expensas, os territórios a eles confiados (COSTA, 2013, p. 16).

Nessa fase ainda inicial das sociedades já era possível perceber impactos no meio ambiente devido a ação do homem, cite-se o aumento exponencial da produção agrícola que se deu via ampliação da área cultivável sem a utilização de tecnologia avançada disponível para o período. Conforme Costa (2013):

Em seu aspecto econômico, a crise deriva da exploração agrícola predatória e extensiva que fora típica do feudalismo. De fato, na época de expansão, o aumento da produção fora conseguido mais com a ampliação da área cultivável do que com a utilização de tecnologia mais avançada. Assim, aquele incremento produtivo era frágil e apresentava limites bem claros, uma vez que só poderia se manter com a anexação constante e indefinida de novas áreas cultiváveis. Quando em algumas regiões houve necessidade de ampliação do cultivo de cereais, com perda de terras até então destinadas à pecuária, a médio prazo, a produtividade agrícola baixou, devido à menor disponibilidade de esterco. Naturalmente, caiu a produção de carne, leite e derivados.

A busca por áreas de cultivo produziu desmatamentos desordenados e isto se refletiu nas condições climáticas, contribuindo para que ocorressem colheitas desastrosas entre 1314-1315; e, de fins de 1315 a meados de 1316 os preços do trigo mais que triplicaram. A fome abriu caminho para várias epidemias e a mortalidade cresceu. Como cada indivíduo gastava mais com a alimentação, consumia menos em bens artesanais, houve a retração deste setor e, consequentemente, também do comércio (COSTA, 2013, p. 18-19). 
Quando a industrialização está em vias de começar a riqueza já havia deixado de ser predominantemente imobiliária e as terras mudam de mãos, saindo dos feudos e transferindo para os capitalistas urbanos, conforme Lefebvre (2001):

As terras escapam aos feudais e passam para as mãos dos capitalistas urbanos enriquecidos pelo comércio, pelo banco, pela usura. Segue-se a "sociedade" no seu conjunto, compreendendo a cidade, o campo e as instituições que regulamentam suas relações, tende a se constituir em rede de cidades, com uma certa divisão do trabalho (tecnicamente, socialmente, politicamente) feita entre as cidades ligadas por estradas, por vias fluviais e marítimas, por relações comerciais e bancárias. Pode-se pensar que a divisão do trabalho entre as cidades não foi nem tão extremada, nem tão consciente que determinasse associações estáveis e pusesse fim às rivalidades e concorrências. Esse sistema urbano não chegou a se instalar. O que se levanta sobre essa base é o Estado, o poder centralizado. Causa e efeito dessa centralização particular, a centralização do poder, uma cidade predomina sobre as outras: a capital (LEFEBVRE, 2001, p. 13).

A grande produção manufatureira, o surgimento dos impérios financeiros e a descoberta do Novo Mundo deram início a Idade Moderna, sociedade com a visão da propriedade com finalidade lucrativa, e, posteriormente, com a ascensão da burguesia impondo sua ideologia de a sociedade ter como princípio a busca pela felicidade, nasce a ideia de que ao Governo cabia a função de garantir os direitos naturais.

Essa época foi marcada pela preocupação com aquisição da propriedade, pois sua posse representava riqueza em detrimento dos impactos que a aquisição de gigantescas porções de terra traria para o meio ambiente.

Com o advento da Revolução Francesa em 1789, tem início a Idade Contemporânea, contrapondo-se ao sistema feudal, onde o direito coletivo passa a ter mais importância que o direito individual, portanto, cabendo ao Estado a tarefa de dispor de instrumentos viabilizadores da garantia da função social da propriedade, tal como descreve Costa (2013):

Com a Revolução Francesa, em 1789, inicia-se a Idade Contemporânea e, contrapondo-se ao sistema feudal consolidado em proposições e valores absolutos e teológicos, a propriedade recebeu nova concepção, nos aspectos jurídicos e político-ideológico. Os bens imóveis foram erigidos, sendo, em contrapartida, ignorados os móveis; os direitos perpétuos à propriedade foram extintos, os privilégios das classes abastadas foram desprezados. As mudanças radicais sofridas na sociedade europeia demarcaram seu apogeu no período da Revolução Francesa, quando se percebeu que o interesse social exigia restrições às prerrogativas individuais, firmando-se sob a nova forma de poder de regulação, o princípio de que o caráter inviolável e sagrado da propriedade não impediam sua utilização destinada ao bem coletivo, mediante justa e prévia indenização pela cessão compulsória da propriedade individual em proveito de ordem pública. Dessa forma, o Estado, em seu contexto organizacional, dispõe de instrumentos viabilizadores do exercício 
de uma função social, sob a égide do direito positivo vigente (COSTA, 2013, p. 29).

A Revolução Industrial provocou aumento explosivo do crescimento demográfico das cidades, principalmente em função da criação de postos de emprego em função da fixação das fábricas nos perímetros urbanos.

O aumento demográfico e o vertiginoso crescimento do comércio impactaram profundamente no crescimento das cidades, sobretudo com relação a organização do trabalho e no aumento da demanda por moradia. A consequência desse fluxo de pessoas para as cidades era assim descrita por Hobsbawn (2011):

$\mathrm{Na}$ era industrial o trabalho passou a ser realizado cada vez mais no ambiente sem precedentes da grande cidade; e isso a despeito do fato de a amais antiquada das revoluções industriais efetuar grande parte de suas atividades em vilas industrializadas de mineiros, tecelões, fabricantes de pregos e correntes e outros trabalhos especializados. Em 1750 só existiam duas cidades na Grâ-Bretanha com mais de 50.000 habitantes - Londres e Edinburgo; em 1801 já havia oito e em 1851, 29, inclusive nove com mais de 100.000 habitantes. Nessa época havia mais britânicos morando em cidades que no campo, e quase um terço da população total vivia em cidades com mais de 50.000 habitantes. E que cidades! Não era apenas o fato de serem cobertas de fumaça e impregnadas de imundice, nem o fato de os serviços públicos básicos - abastecimento de água, esgotos sanitários, espaços abertos etc. - não poderem acompanhar a migração maciça de pessoas, produzindo assim, sobretudo depois de 1830 epidemias de cólera, febre tifoide e o pagamento assustador de tributo constante aos dois grandes grupos de assassinos urbanos do século XIX - a poluição do ar e das águas, ou doenças respiratórias e intestinais (HOBSBAWN, 2011, p. 76-77).

Esse cenário favoreceu a evolução e expansão das sociedades propiciando o surgimento dos grandes centros urbanos, e com eles novos problemas, tais como lixo acumulado pelos grandes centros, esgotos e detritos de tipos diversos sendo jogados no meio ambiente. Com isso, a sociedade passa a conviver com um cenário de transformações tecnológicas e climáticas em que as ações humanas são apontadas como a principal causa da destruição do meio ambiente. Nesse sentido:

A humanidade está vivendo em uma época de mudanças ou transformações radicais tanto do ponto de vista tecnológico como climático. As ações humanas são apontadas como fatores de destruição do Planeta Terra, da natureza com seus ecossistemas, acarretando mudanças climáticas violentas, poluição dos espaços terrestre, marítimo e espacial, bem como o efeito estufa e as crises hídrica e energética (BIZAWU; GOMES, 2016, p. 16).

Nesse contexto de crescimento o Estado assume papel de destaque devendo adotar mecanismos para controlar o crescimento e desenvolvimento das cidades de forma a regular a convivência e o tratamento dado à propriedade. 


\section{DESENVOLVIMENTO DOS CENTROS URBANOS}

Com o advento da Revolução Industrial e o aumento do número de fábricas nos centros urbanos houve necessidade de mão de obra para preencher os novos postos de trabalho com consequente redução do número de trabalhadores do campo. Segundo Hobsbawn (2011), para a expansão do comércio, além de pessoas para produzir, seria necessário também grande quantidade de pessoas para formar um mercado consumidor que, segundo o autor, só poderia se dar de quatro formas:

O mercado interno, por grande e crescente que fosse, só podia crescer de quatro maneiras importantes, e três delas com toda a probabilidade não seriam excepcionalmente rápidas. Poderia haver crescimento da população, que cria mais consumidores (e, naturalmente, mais produtores); uma transferência de pessoas, das rendas não monetárias para rendas monetárias, o que cria mais clientes; um aumento da renda per capta, o que cria melhores clientes; e o advento de bens produzidos industrialmente, em substituição a forma mais antiga de manufaturas ou importações (HOBSBAWN, 2011, p. 31-32).

Com relação ao crescimento da população no período, Hobsbawn (2011) explica que a mortalidade com quase toda certeza não foi reduzida por influência da medicina, mas que fatores como mudanças econômicas, sociais e de outras naturezas ambientais foram os motivos para a sua expressiva redução, que a rigor se traduz em aumento da quantidade de mão de obra mais barata com consequente estímulo ao crescimento econômico.

Obviamente o crescimento populacional não tem o condão de explicar o grande crescimento do comércio no período pós Revolução Industrial, que certamente seria muito melhor explicado pelos investimentos em transportes por rios, canais e estradas que fomentaram o desenvolvimento industrial e o comércio via mercado interno, sobretudo na Inglaterra, assim explicado por Hobsbawn (2011):

Melhorias muito substanciais e dispendiosas em transportes - por rios, canais e mesmo estradas de rodagem - foram realizadas desde o começo do séc. XVIII, a fim de diminuir o custo proibitivo de movimentar cargas terrestres: em meados do século o transporte por terra para $30 \mathrm{~km}$ podia dobrar o custo de uma tonelada de mercadorias. Não sabemos com certeza até onde esses meios de transporte foram importantes para o desenvolvimento da industrialização, mas não resta dúvida de que o estímulo foi dado pelo mercado interno, e principalmente pela crescente procura de alimentos e combustível nas cidades (HOBSBAWN, 2011, p. 60). 
A migração desordenada do campo para as cidades aliada à falta de planejamento urbano implicou em bolsões de pessoas vivendo à margem da sociedade em razão da escassez de moradia causando sérios problemas ambientais e sociais.

O rápido crescimento das cidades e dos centros urbanos implicou em constantes adaptações no desenho das cidades. Na Idade Média havia a tendência a uma arquitetura urbana voltada para a religiosidade e segurança tal como cidades do século XVIII que traziam em sua construção grande influência barroca, conforme explica Goitia (2003):

No campo do urbanismo, será no século XVIII que a arte barroca da composição das cidades atingirá o seu apogeu, transformando-se em verdadeira arte urbana. A cidade foi concebida tal como era vista. Contemplava-se o mundo como um panorama. A título de exemplo, tem-se a Rue de Rivoli em Paris, onde o traçado contínuo de suas linhas corre em perspectiva, provocando uma forte impressão estética, ou mesmo as residências reais da Europa do século XVIII, como Versailles, Nanci, Dresden, Kopenhague ou São Petersburgo, que adotaram a mesma concepção estrutural (GOITIA, 2003, p. 126-128).

A arquitetura influenciava as construções de modo a atender o crescimento comercial e o trânsito das pessoas dentro das cidades devido ao intenso comércio da época. Não havia, nesse período, preocupação com o impacto que o crescimento desordenado traria ao meio ambiente. Conforme explica Maluf (2010), não se pensava à época em políticas urbanas de desenvolvimento das cidades. A falta de planejamento urbano se refletia, por exemplo, em situações como na cidade de Paris, que cresceu de forma irregular, com a população quase dobrando e a superfície habitada aumentada de apenas um terço em um curto espaço de tempo dando indícios que algo haveria de ser feito pensando no futuro.

O comércio se desenvolveu rapidamente e com ele a sociedade burguesa, em sua grande maioria composta por mercadores e grupos fixados nos centros de comércio ou centros urbanos. Nesses locais encontravam-se portos, mercados e vilas para onde ia grande parte dos moradores do meio rural em busca de melhores oportunidades, surgindo os núcleos urbanos. Segundo Lefebvre (2001), as cidades acumularam riquezas e os centros urbanos riqueza monetária, obtida pela usura e pelo comércio, assim destacado:

Nesses centros, prospera o artesanato, produção bem distinta da agricultura. As cidades apoiam as comunidades camponesas e a libertação dos camponeses, não sem aproveitarem disso em seu próprio benefício. Em suma, são centros de vida social e política onde se acumula não apenas riquezas como também os conhecimentos, as técnicas e as obras (obras de arte, monumento).

A própria cidade é uma obra, e esta característica contrasta com a orientação irreversível na direção do dinheiro, na direção do comércio, na direção das 
trocas, na direção dos produtos. O uso principal da cidade, isto é, das ruas e das praças, dos edifícios e dos monumentos, é a Festa (que consome improdutivamente, sem nenhuma outra vantagem além do prazer e do prestígio, enormes riquezas em objetos e dinheiro) (LEFEBVRE, 2001, p. 12).

Os centros urbanos tiveram o seu crescimento impulsionado pelos avanços trazidos pela Revolução Industrial que estimulava a concentração de pessoas nestes locais aumentando a importância do planejamento urbano, tal como leciona Maluf (2010):

O planejamento urbano logo se tornou imprescindível para a estruturação adequada das cidades. Estudos recentes apontam para o fato de que os continentes mais urbanizados são os mais modernos, pois na realidade a cultura de hoje é primordialmente urbana. (Publicação da Geografical Review aponta que $44 \%$ da população vive na zona urbana na Austrália, 24\% nos EUA, 19\% na Europa, 11\% na América do Sul, 5\% na Ásia e 2,5\% na África) (MALUF, 2010, p. 96).

Nesse contexto, não havia como evitar a criação de regras de convívio dentro das cidades, principalmente com respeito à propriedade privada dada sua importância de grandes proporções ao representar sinônimo de poder e riqueza.

Com o advento de um novo mundo de comércio e valorização do capital era necessário ter mais responsabilidades com o bem estar coletivo em detrimento do individual. Desta forma, o mau uso da terra e os prejuízos trazidos ao meio ambiente poderiam ser evitados com a criação de mecanismos de restrição à utilização da propriedade privada e a valorização do pensamento voltado ao bem estar coletivo.

Nesse ambiente de valorização da propriedade e do coletivo surgem as limitações ao direito de propriedade urbana de modo a restringir a forma de utilização da propriedade para não afetar a coletividade. Segundo Maluf (2010):

Evidencia-se, portanto, a natureza jurídica das limitações ao direito de propriedade como uma subordinação do direito de propriedade privado ao interesse precípuo da coletividade, advinda de normas de direito público e de direito privado e que aparecem de forma mais corriqueira como obrigações positivas ou obrigações de fazer, formulando imposições que apontam para o dever de o bem o bem visando sempre o interesse público (MALUF, 2010, p. 105).

A ideia de que ser dono implicaria em poder absoluto sobre o bem não predomina mais dentro da premissa de primazia do interesse público sobre o interesse privado. Segundo Diniz (2002), deve haver uma subordinação do direito de propriedade privada aos interesses públicos e convenções sociais, assim explicado:

As restrições à propriedade, por sua vez, pressupõem a ideia de subordinação do direito de propriedade privada em face dos interesses públicos e das 
conveniências sociais. São imprescindíveis ao bem-estar coletivo e à própria segurança da ordem econômica do país. Assim, atingem a estrutura legal do domínio em toda a sua extensão ou em parte dela. Configuram um sacrifício dos interesses particulares subordinado ao interesse público. Entre essas restrições podem-se apontar: a desapropriação; o tombamento; as atinentes ao direito de construir (exigindo que os prédios obedeçam a certo alinhamento, obrigando o proprietário a murar o terreno, calçar o passeio) (DINIZ, 2002, p. 217-224).

Percebe-se, portanto, o início da preocupação do Estado com o planejamento do crescimento das cidades e criação de meios capazes de regular o uso e ocupação do solo aliado às características construtivas para garantir o bem estar coletivo e equilíbrio ambiental, ainda que para isso fosse necessário a interferência direta no exercício do direito de propriedade, assim destacado por Maluf (2010):

Diversas limitações são impostas à propriedade urbana em prol da coletividade visando o estabelecimento da população no espaço urbano, denominado cidade sustentável; para tanto, defende Miguel Reale a ideia da cidade como um "bem cultural", e não apenas como um aglomerado de pessoas. Em consonância com o princípio constitucional da "função social" da propriedade, teve como consequência a elaboração de institutos e figuras jurídicas, cuja finalidade foi adequar a propriedade individual à nova imagem da realidade urbana, o que, naturalmente, não pode deixar de suscitar reações por parte dos que se apegam a superadas prerrogativas (MALUF, 2010, p. 116).

Como reflexo da preocupação do Estado na proteção do direito à propriedade, destaca-se a evolução das normas que tratam da matéria como, por exemplo, art. 147 da CR/1988, arts. 1.228 e 1.229 do CC/2002, Estatuto da Cidade (Lei $n^{\circ}$ 10.257/2001) e outras de igual importância como Plano Diretor, normas de delimitação de zona urbana e uso e ocupação do solo com o fulcro de tornar sadio o crescimento das cidades de forma a não prejudicar o bem estar coletivo, e o meio ambiente.

A partir do momento em que o Estado assume a responsabilidade, ainda que de forma embrionária, do controle e restrição do crescimento inicia-se um processo de planejamento urbano das cidades com o intuito de se conduzir ao crescimento sustentável. No Brasil, segundo Kapp (2012), a institucionalização do direito à cidade não teve caráter revolucionário, mas sim de reforma urbana, o que segundo a autora, seria uma forma de amenizar a dicotomia entre a cidade legal e a clandestina.

Para Kapp (2012) essa institucionalização no Brasil do caráter de reforma urbana é limitado e poderia gerar expedientes para neutralizar as críticas nessa sociedade, impedindo avanços da democracia direta, assim explicado: 
[...] No primeiro caso, caberia aplicar o argumento de Tushnet (1984) de que o engajamento por leis, planos e instrumentos jurídicos tende a ser inútil porque, no melhor dos casos resulta em documentos de conteúdo escorregadio e de uma linguagem que permite apropriações por agendas opostas, ao ponto de simplesmente legitimar o status quo. No segundo caso, caberia o contra-argumento de Mitchell (2003), de que pressões populares podem, sim, levar o Estado de Direito a proteger os socialmente mais fracos e a fortalecer agendas emancipatórias (KAPP, 2012, p. 466-467).

Segundo Maricato (2000), a legislação brasileira possui rigoroso e amplo aparato regulatório que controlam a produção do espaço urbano, e, portanto, não é pela falta de material legislativo que as cidades crescem de modo desorganizado, mas sim pela desconsideração da ilegalidade vivida pela maioria da população:

Nunca é demais repetir que não é por falta de planos e nem de legislação urbanística que as cidades brasileiras crescem de modo predatório. Um abundante aparato regulatório normatiza a produção do espaço urbano no Brasil - rigorosas leis de zoneamento, exigente legislação de parcelamento do solo, detalhados códigos de edificações são formulados por corporações profissionais que desconsideram a condição da população urbana brasileira em relação à moradia e à ocupação da terra, demonstrando que a exclusão social passa pela lógica da aplicação discriminatória da lei (MARICATO, 2000, p. 147).

A autora afirma que no Brasil a ocupação ilegal além de permitida é também parte integrante do modelo de desenvolvimento urbano brasileiro, justificado pela existência de uma detalhada legislação urbanística, que de acordo com interesses é flexibilizada pela corrupção na cidade legal e de outro lado pela ilegalidade na provisão de grande parte das moradias urbanas como forma de manutenção do baixo custo da força de trabalho criando um gigantesco hiato entre a gestão e a lei.

O desenvolvimento dos centros urbanos, como dito, fez surgir a necessidade do planejamento urbano de modo sustentável. A criação de leis e normas eficazes continua sendo um importante instrumento para a que os espaços urbanos sejam criados de modo a garantir o crescimento sustentável. De nada adianta um complexo aparato jurídico composto por leis rigorosas se não houver maior participação popular inclusive na criação das leis e a boa gestão na sua aplicação.

\section{PLANEJAMENTO URBANO E SUSTENTABILIDADE}


Com a Revolução Industrial houve aumento exponencial da produção, pois o que antes era feito de forma artesanal, principalmente bens de consumo, passou a ser feito de forma manufaturada, fazendo chegar à população produtos industrializados em escala muito maior. 0 primeiro efeito desse processo foi o gigantesco deslocamento de pessoas do meio rural para o meio urbano na busca de melhores condições de trabalho oferecidas pelas fábricas, fazendo com que o trabalhador rural de outrora passasse agora a vender sua força de trabalho em troca de remuneração.

Uma primeira consequência negativa desse processo foi a aglomeração de pessoas em subúrbios e lugares sem o menor conforto devido ao aumento da demanda por moradia e a falta de preparo das cidades para receber o volume de pessoas que chegavam nestes centros urbanos.

Segundo Lefebvre (2001), o processo de industrialização é sem dúvida o motor das transformações na sociedade, assim explicado pelo autor:

Para representar e expor a "problemática urbana", impõe-se um ponto de partida: o processo de industrialização. Sem possibilidade de contestação, esse processo é, há um século e meio, o motor das transformações na sociedade. Se distinguirmos o indutor e o induzido, pode-se dizer que o processo de industrialização é indutor e que se pode contar entre os induzidos os problemas relativos ao crescimento e à planificação, as questões referentes à cidade e ao desenvolvimento da realidade urbana, sem omitir a crescente importância dos lazeres e das questões relativas à cultura.

A industrialização caracteriza a sociedade moderna. O que não tem por consequência, inevitavelmente, o termo "sociedade industrial", se quisermos defini-la. Ainda que a urbanização e a problemática do urbano figurem entre os efeitos induzidos e não entre as causas ou razões indutoras, as preocupações que essas palavras indicam acentual de tal modo que se pode definir como sociedade urbana a realidade social que nasce à nossa volta. Esta definição contém uma característica que se torna de capital importância (LEFEBVRE, 2001, p. 11).

De acordo com Lefebvre(2001), há na atualidade um aprofundamento do processo induzido em que ele chama de "implosão-explosão" da cidade em que a maior parte do território dos grandes países sofrem o fenômeno urbano tais como Europa e Estados Unidos, implicando diversas consequências:

[...] Esse território está encerrado num tecido urbano cada vez mais cerrado, não sem diferenciações locais e sem ampliação da divisão (técnica e social) do trabalho para as regiões, aglomerações e cidades. Ao mesmo tempo, nesse tecido e mesmo noutros lugares, as concentrações urbanas tornam-se gigantescas; as populações se amontoam atingindo densidades inquietantes (por unidade de superfície ou de habitação). Ao mesmo tempo ainda, muitos núcleos urbanos antigos se deterioram ou explodem. Escritórios substituem apartamentos nos centros urbanos. Às vezes (nos Estados Unidos) esses centros são abandonados para os "pobres" e tornam-se guetos para os 
desfavorecidos. Às vezes, pelo contrário, as pessoas mais abastadas conservam fortes posições no coração da cidade (em redor do Central Park em New York, no Marais em Paris) (LEFEBVRE, 2001, p. 18).

Essa nova sociedade urbana, caracterizada como tecido urbano ${ }^{5}$ tem segundo o autor o poder de penetração nos campos alterando o sistema de vida destes locais ao trazer elementos do sistema urbano como: água, eletricidade, gás, carro, televisão, utensílios de plástico, mobiliários e elementos do sistema de valores compostos pelo modo urbano como danças e canções, costumes e as preocupações com a segurança e o futuro traduzidas em uma racionalidade levada pela cidade.

Na discussão acerca do tecido urbano e da nova sociedade urbana surgem os conceitos de urbanidade e urbanismo. A urbanidade pressupõe pessoas utilizando espaços públicos, diversidade de perfis, interação entre os espaços abertos públicos e os espaços fechados, diversidade do modo de transporte e deslocamento e pessoas interagindo em grupo. Já o urbanismo é de caráter mais técnico composto pelo desenho urbano, projeto das cidades e o planejamento urbano propriamente dito.

A indústria e a industrialização transformam a realidade urbana e o social urbano é substituído pelo econômico industrial, o que segundo Lefebvre (2001) afeta diretamente o modo de vida e o habitat das pessoas, por exemplo, com a criação dos subúrbios:

Os subúrbios, sem dúvida, foram criados sob a pressão das circunstâncias a fim de responder ao impulso cego (ainda que motivado e orientado) da industrialização, responder à chegada maciça dos camponeses levados para os centros urbanos pelo "êxodo rural" (LEFEBVRE, 2001, p. 24).

A industrialização fomenta a ampliação da urbanização e com ela a generalização da sociedade urbana mostrada inicialmente pelo seu lado negativo representado pela explosão da cidade e a primazia pela realidade socioeconômica em detrimento da realidade social. Em um mundo onde não há mais como se considerar a industrialização separada da urbanização, há que se pensar em um planejamento urbano voltado para o crescimento na direção do desenvolvimento de uma sociedade urbana sustentável. Segundo Lefebvre (2001) há três tipos de urbanismo:

a) Urbanismo dos homens de boa vontade (arquitetos, escritores). [...] Geralmente, ligam-se a um humanismo: o antigo humanismo clássico e liberal. [...] Sua ideologia, ou antes, seu idealismo provém frequentemente de modelos agrários, adotados de modo irrefletido por seu raciocínio: a aldeia, a comunidade, o bairro, o citadino-cidadão que será adotado com edifícios cívicos etc.

\footnotetext{
${ }^{5}$ Segundo Lefebvre (2001), o tecido urbano pode ser descrito utilizando o conceito de ecossistema, unidade coerente constituída ao redor de uma ou várias cidades, antigas ou recentes. Ela é o suporte de um "modo de vida" mais ou menos intenso ou degradado: a sociedade urbana.
} 
b) Urbanismo dos administradores ligados ao setor público (estatal). Este urbanismo se pretende científico. [...] Esse urbanismo tecnocrático e sistematizado, com seus mitos e sua ideologia (a saber, o primado da técnica) não hesitaria em arrasar o que resta da Cidade para dar lugar aos carros, às comunicações, às informações ascendentes e descendentes.

c) Urbanismo dos promotores de venda. Eles o concebem e realizam, sem nada ocultar, para o mercado, visando o lucro. Fato novo, recente, é que eles não vendem mais uma moradia ou imóvel, mas sim urbanismo. Com ou sem ideologia, o urbanismo torna-se valor de troca. O projeto dos promotores de vendas se apresenta como ocasião e local privilegiado: lugar de felicidade numa vida cotidiana miraculosa e maravilhosamente transformada (LEFEBVRE, 2001, p. 32).

A industrialização, explosão do urbanismo e os avanços tecnológicos de produção e de desenvolvimento comercial propiciaram como dito, o aumento demográfico nos centros urbanos e importante alteração no modo de vida destes centros, o que implicou na exigência de um bom planejamento urbano ${ }^{6}$. Dentro de uma perspectiva de planejamento urbano efetivo, há que se ter institutos jurídicos capazes de garantir sua eficácia, como, por exemplo, a Lei № 10.257/2001, Estatuto da Cidade, que regulamentou os arts. 182 e 183 da CR/1988, em especial o Plano Diretor previsto no art. 182 e o Ministério das Cidades.

Segundo Kapp (2012), a regulamentação dos arts. 182 e 183 pelo Estatuto da Cidade representou um marco da noção de direito à cidade e que possibilitou a criação de uma nova ordem jurídica urbanística, conforme afirma:

[...] O Brasil incorporou formalmente a noção de 'direito à cidade' em [seu] sistema legal. O processo possibilitou a criação de uma ordem jurídicourbanistica na qual as chamadas funções sociais da propriedade e da cidade são declaradas prioritárias, bem como a criação de um Ministério das Cidades para articular políticas habitacionais e urbanas, um Sistema Nacional e um Fundo Nacional de Habitação, e inúmeros órgãos e conselhos estaduais e municipais para detalhá-las e pô-las em prática (KAPP, 2012, p. 466).

Um dos problemas, segundo Silva (1991), é que o direito à cidade institucionalizado no Brasil, não teve o caráter revolucionário, mas ao contrário, adotou o caráter de reformismo com a finalidade de amenizar os contrastes entre a cidade legal e a ilegal, assim destacado:

Há de se convir então que o direito à cidade institucionalizado no Brasil não tem o caráter revolucionário. Declaradamente, a "bandeira de luta" da reforma urbana desde os anos 1980, visa, sobretudo, a amenizar a dicotomia entre a cidade legal e clandestina, cidade moderna e precária, cidade rica e pobre (SILVA, 1991, p. 7).

\footnotetext{
${ }^{6}$ Entende-se por planejamento urbano a técnica de diagnóstico e proposição de soluções para os problemas das cidades, pensando em seu futuro. Engloba todos os aspectos da vida urbana, tais como a infraestrutura de serviços, o sistema viário e a localização das diversas atividades.
} 
Desta forma o Brasil adotou como resposta à crise urbana a ideia de reforma urbana sem se preocupar com a ideia de revolução das instituições. Apesar da importância da criação de uma ordem jurídica com prioridade às funções sociais da propriedade e da cidade, criação do Ministério das Cidades com a função de articular as políticas habitacionais e urbana não teria o êxito desejado sem que houvesse uma mudança, dentro das estruturas e instituições existentes, promovida através de uma revolução nesses institutos.

A adoção dessa ideia reformista adotada pelo Brasil quando de sua incorporação da noção do direito à cidade, levanta duas questões, quais sejam, o argumento mais frágil de Tushnet (1984) em que essa incorporação se deu de forma mais limitada e poderia se constituir em um dos vários instrumentos para a neutralização das críticas nessa sociedade ou o contra argumento de Mitchell (2003) de que as pressões populares poderiam levar a um avanço paulatino rumo a mais espaços de democracia direta. Pelo primeiro argumento haveria o engajamento através de leis, planos e instrumentos jurídicos que tenderia a ser inútil e o segundo resultaria em uma gama de documentos, mas que devido a sua linguagem e conteúdo "escorregadio" permitiria sua utilização por agendas opostas de forma a simplesmente legitimar o status quo, contrário ao segundo argumento onde as pressões populares através de maior participação popular forçariam o Estado a proteger os socialmente mais fracos.

No Brasil, de acordo com Maricato (2000), o ciclo de mobilização não conseguiu gerar uma mudança de rota que orientasse o crescimento das cidades, situação que para Kaap (2012) fez com que as operações especulativas continuassem com maior importância na determinação do espaço urbano:

A disputa dos capitais por localização e pelo valor de uso complexo das cidades, a indústria imobiliária e as operações especulativas continuam muito mais determinantes na produção do espaço urbano do que qualquer participação popular nas decisões do Estado ou qualquer função social da propriedade (KAPP, 2012, p. 467).

Apesar da evidente evolução institucional com abertura de novos canais de participação popular e o aprimoramento politicamente correto dos discursos, segundo Maricato (2000) não se percebe grandes reflexos nas cidades, ao contrário, elas estão piorando e esses avanços sequer chegam à população, administração pública ou no trabalho técnico onde deveria se manifestar na ideia de reforma urbana tendo como foco central a justiça urbana.

O ponto principal em torno dos institutos criados com o propósito de garantir o crescimento sustentável das cidades é saber se apesar de preverem intenções e objetivos 
importantes em seu texto se elas serão convertidas em medidas e atitudes práticas para a efetivação de sua realização.

De acordo com Kapp (2012), é de se prever que esse efeito estaria pré-definido no Estatuto da Cidade, pois a legislação federal que estabelece a função social da propriedade é a mesma que a torna inteiramente dependente de instâncias legislativas, inserindo-as em um ambiente onde os agentes privados exercem influência de tal forma a adiar sua aplicação.

Não há como negar que a formalização da proteção e do fortalecimento de direitos no Estatuto da Cidade foi de grande importância, mas há que se ter como premissa que a principal condição para transformar o processo de desenvolvimento urbano é a reforma da ordem legal.

Assim, em não havendo uma efetiva participação popular no processo de construção destes instrumentos, obviamente se teria o argumento de fragilidade levantado por Tushnet do caráter vago destes documentos e traria como consequência margem para uma interpretação que privilegie o Estado de modo que a participação se tornaria um processo meramente deliberativo ou simplesmente consultivo.

Não adianta a elaboração de instrumentos por técnicos e administradores públicos, pois dessa forma a participação popular não terá o status de autogestão e nem a autonomia dos habitantes, mas ao contrário, o sistema será burocratizado e com a diminuição do engajamento. De acordo com Kapp (2012) essa situação pode ser vista principalmente em áreas habitadas pela população política e economicamente mais pobre, onde o cerne da ideia ao direito à cidade não é considerado:

[...] Isso vale muito particularmente para o contexto de intervenções em áreas habitadas pela população política e economicamente mais pobre, isto é, naquelas porções da cidade para as quais a ideia da reforma urbana e o próprio Estatuto foram formulados. Nesse âmbito, técnicos e administradores tendem a tomar a participação como uma tarefa entre outras, a ser realizada pelo "pessoal do social" (os assistentes sociais que compõem as equipes de órgãos públicos e empresas privadas) sem influência decisiva sobre os processos e produtos de intervenções urbanísticas. Ora, a participação não é apenas uma entre outras ideias relacionadas ao direito à cidade. Ela é seu cerne (KAPP, 2012, p. 467).

Estar-se-ia, portanto, diante do urbanismo dos administradores, definido por Lefebvre (2001) como tecnocrático e sistematizado, sempre primado pela técnica e onde a cidade tal como dita pelo autor, espaço de convívio social e de harmonia de diferentes grupos e etnias, está destinada à destruição para dar lugar aos veículos e às informações ascendentes e descendentes. 
O planejamento das cidades não pode se limitar aos critérios técnicos, contemplando apenas seus aspectos arquitetônicos. O planejamento deve ser feito com foco na sustentabilidade tendo como premissa principal o direito à cidade, reestruturação das relações sociais, políticas e econômicas, objetivando o direito à liberdade, individualização social e o direito ao habitat e ao habitar, que segundo Lefebvre (2011) significa:

[...] determinar como se quer habitar, incluindo as características de espaços privados e públicos, as relações entre uns e outros, com o meio natural, com a vizinhança imediata e mediata, com as centralidades e redes urbanas mais abrangentes e assim por diante (LEFEBVRE, 2001, p. 135).

Na prática instrumentos como Estatuto da Cidade e o Plano Diretor mencionam e enfatizam a participação popular e a função social da propriedade, mas ficam restritos à mera formalidade de seu registro não tendo a aplicação prática como deveria. A explicação de o porque isso acontece é dada por Kaap (2012):

[...] No entanto, talvez pelo fato de terem sido elaborados em grande parte por terceiros e com participação social reduzida (ao menos os registros a esse respeito são escassos e surpreendentemente semelhantes entre si), os Planos Diretores trazem pouca articulação entre tais princípios e as especificidades locais. Muitos destacam o incentivo a formas alternativas de construção, à criação de cooperativas, associações e sindicatos habitacionais autogestionários e a capacitação de iniciativas coletivas por meio de assessoria técnica, sem explicar como isso seria implementado (KAPP, 2012, p. 472).

Segundo a autora (2012), o fato de muitos técnicos estarem convencidos de que os instrumentos que atacam o direito privado são na prática inviáveis fazem com que muitos deles de grande importância como o direito de superfície, outorga onerosa e medidas como IPTU progressivo não sejam utilizados. Para possibilitar a justa execução dos planos é de suma importância a conscientização da inclusão da população na avaliação dos benefícios e prejuízos da aplicação do Estatuto da Cidade com posterior análise das reivindicações feitas com o objetivo de modificar as práticas políticas e administrativas.

Outro ponto levantado por Kaap (2012) é o descompasso entre os programas federais e os problemas enfrentados pelas prefeituras no dia a dia devido a falta de órgãos responsáveis por políticas públicas habitacionais e urbanas. Essa situação obriga diversos órgãos municipais a absorverem atribuições que não são de sua competência acarretando no distanciamento dos órgãos públicos dos problemas urbanos, em razão disso também, os planos federais acabam não conseguindo refletir as necessidades urbanas locais.

De acordo com Maricato (2000) existe a cidade legal e a cidade ilegal. Para a cidade ilegal não há planos e nem ordem e ela não é conhecida por suas dimensões ou características, o que de 
certa forma é reflexo do urbanismo de planejamento. A regulação urbanística adotada no Brasil tem comprometimento com legal e ignora a cidade ilegal representada pelas ocupações ilegais do solo urbano, assim explicada:

A exclusão urbanística, representada pela gigantesca ocupação ilegal do solo urbano, é ignorada na representação da "cidade oficial". Ela não cabe nas categorias do planejamento moderno /funcionalista pois mostra semelhança com as formas urbanas pré-modernas. É possível reconhecer nas favelas semelhanças formais com os burgos medievais. Ela não cabe também no contexto do mercado imobiliário formal/legal, que corresponde ao urbanismo modernista. Ela não cabe ainda, de modo rigoroso, nos procedimentos dos levantamentos elaborados pela nossa maior agência de pesquisa de dados, o IBGE (Instituto Brasileiro de Geografia e Estatística). E, por incrível que pareça, os órgãos municipais e de aprovação de projetos, as equipes de urbanistas dos governos municipais e o próprio controle urbanístico (serviço público de emissão de alvarás e habite-se de construções), frequentemente desconhecem esse universo. Mesmo nas representações cartográficas é de hábito sua ausência (MARICATO, 2000, p. 122).

Segundo Maricato (2000), modelo modernista/funcionalista adotado no Brasil tem a ilegalidade funcional para relações políticas arcaicas, mercado imobiliário especulativo e aplicação arbitrária da lei baseado na dominação econômica e política, mas em contrapartida disfuncional para a sustentabilidade ambiental, relações democráticas mais igualitárias, qualidade de vida urbana e ampliação da cidadania. A segregação territorial constatada por essa separação entre cidade legal e ilegal trazia problemas que lhe são inerentes: falta de saneamento ambiental, riscos de desmoronamentos, enchentes, violência e exclusão social.

Esse modelo adotado durante séculos por países centrais do mundo capitalista sofreu a influência de ideias neoliberais adotando padrões importados do chamado primeiro mundo apoiado na centralização e na racionalidade do aparelho do Estado e definia os padrões de uso e ocupação do solo, mas era aplicado apenas na cidade formal caracterizando a cidades brasileiras pela modernização excludente.

Imputa-se a culpa da modernização excludente à falta de leis capazes de regular o uso e ocupação do solo, mas que segundo Maricato (2000), o problema está nos interesses de grandes grupos econômicos ligados principalmente à especulação imobiliária conforme explica:

Não é por falta de Planos Urbanísticos que as cidades brasileiras apresentam problemas graves. Não é também, necessariamente, devido à má qualidade desses planos, mas por que seu crescimento se faz ao largo dos planos aprovados nas Câmaras Municipais, que seguem interesses tradicionais da política local e grupos específicos ligados ao governo de plantão. 0 "planodiscurso" cumpre um papel ideológico (Villaça, 1995) e ajuda a encobrir o motor que comanda os investimentos os investimentos urbanos. No caso das 
metrópoles, além dos grupos locais, o capital imobiliário e as empreiteiras contam sempre na definição dos investimentos que não obedecem a nenhum plano explícito (MARICATO, 2000, p. 124).

O Brasil tem uma das sociedades mais desiguais do mundo e sem dúvida o modelo de planejamento urbano adotado contribuiu para essa situação, principalmente na formação de um mercado imobiliário restrito e especulativo. O material à disposição do gestor, como a lei de zoneamento, código de obras, código visual, leis de parcelamento do solo, se utilizados de forma restrita à cidade legal em detrimento da cidade ilegal, em que se tem a sua aplicação flexível, acaba institucionalizando a ilegalidade.

Como dito, não é por falta de leis que a cidade cresce de forma desordenada, mas a forma como são aplicadas, ou seja, as circunstâncias e os interesses individuais de determinados grupos fazem com que o Plano Diretor, por exemplo, fique desvinculado da gestão urbana.

A ampliação e efetivação da participação popular nas decisões são de suma importância para a elaboração de leis com o objetivo de atender amplamente a todos, contemplando habitação social, transporte público, saneamento e segurança. Sem esses requisitos o resultado, segundo Maricato (2000), seria planejamento urbano para alguns, mercado para alguns, lei para alguns, modernidade para alguns, cidadania para alguns. A autora (2000) deixa claro seu pensamento:

A história do planejamento urbano no Brasil mostra a existência de um pântano entre sua retórica e sua prática, já que estava imerso na base fundante marcada por contradições: direitos universais, normatividade cidadã - no texto e no discurso - versus cooptação, favor, discriminação e desigualdade - na prática da gestão urbana (MARICATO, 2000, p. 135).

Importante, portanto, discutir se a cidade está sendo usada de forma igualitária e como o princípio da distribuição dos encargos e benefícios pode influenciar para produção de uma cidade com igualdade para todos.

\section{O USUFRUTO EQUITATIVO DA CIDADE E O PRINCÍPIO DA JUSTA DISTRIBUIÇÃO DOS ENCARGOS E BENEFÍCIOS}

As cidades caracterizam-se pela interação de diversos tipos de raças, credos, classes sociais e gêneros. Não obstante a isso devem ser planejadas e construídas de forma a permitir moradia digna, educação, segurança e ambiente de qualidade de forma a produzir maior integração social.

Para tanto, os governos devem promover o acesso igualitário aos benefícios da cidade garantindo a participação democrática nas decisões, exercício de direitos fundamentais, 
sustentabilidade, democracia e justiça social com o objetivo de ter o usufruto equitativo da cidade com a justa distribuição de seus encargos e benefícios.

O crescimento desordenado e sem planejamento das cidades cria cenários antagônicos onde de um lado estão os moradores dos centros urbanos (representados pela cidade legal ou formal) e de outro a classe menos favorecida (representada pela cidade ilegal ou informal) que vive à margem da sociedade e distante de onde se encontram os equipamentos públicos que dão acesso, por exemplo, à saúde, lazer e melhor qualidade de vida.

Para garantir acesso igualitário aos benefícios da cidade é necessário reduzir o distanciamento e a marginalização dos moradores de áreas fora da área urbana, levando a esses locais equipamentos públicos, como praças, urbanização, escola e saúde de forma a integrar os moradores à sociedade.

Um bom exemplo dessa situação é o programa favela-bairro no Rio de Janeiro onde apesar da indicação pela remoção forçada dos moradores o projeto tomou rumos contrários na condução de formas para adequar a urbanização na favela sem a sua descaracterização garantindo infraestrutura e regularização fundiária.

De acordo com Kaap (2015), nesse programa foram adotadas medidas interventivas para o saneamento básico, sistema de drenagem, viário, reflorestamento, iluminação pública, coleta de lixo, criação de creches, relocação de moradores, construção de praças e parques, construção de passarela e criação de programas de geração de renda.

A construção ou melhoramento de equipamentos públicos nos espaços da cidade levam consequentemente à valorização dos imóveis nas imediações. Em Belo Horizonte pode-se citar como exemplo a criação da linha verde (corredor exclusivo para ônibus) e a Cidade Administrativa, que gerou um grande aumento do valor dos imóveis da região devido ao abastecimento de melhores condições de transporte público.

Há, portanto, ganho imobiliário muito grande pelos proprietários de imóveis localizados nas regiões onde houve o investimento público, sem a contrapartida nas demais áreas da cidade. Os empreendimentos públicos devem ser priorizados para o atendimento da demanda social, ainda que sem relação direta com a população e com o caráter social dos investimentos, devem ser orientados pela prioridade de sua alocação com a relação da distribuição de seus benefícios diretos e indiretos. Agindo assim, o Poder Público assegura a socialização dos investimentos em detrimento da privatização de seus benefícios representado pela função social da gestão urbana. 
Para se evitar a privatização da utilização desses benefícios o gestor deve adotar políticas que garantam a efetivação da função social, sobretudo observando previsões legais como a dos

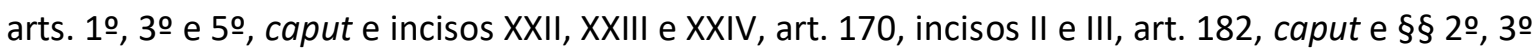
e 4ㅇ da CR/1988, bem como o Estatuto da Cidade, Lei no 10.257/2001, e a Lei no 6.766/1979, Lei de Uso e Parcelamento do Solo.

A efetiva aplicação desses institutos aliados a outros, como planejamento urbanístico, com a finalidade de gerar recursos financeiros e fundiários, observação dos impactos da urbanização sobre o mercado imobiliário, IPTU progressivo, contribuição de melhoria, plano diretor, lei de uso e ocupação do solo, outorga onerosa da alteração do uso e do direito de construir, transferência do potencial construtivo, declaração de abandono de imóvel nos termos do art. 1.276, § 2을 do CC/2002 e a desapropriação imobiliária urbana, darão condições ao gestor público de alcançar igualdade no uso da cidade, bem como uma justa distribuição dos encargos e benefícios.

O princípio da justa distribuição de encargos e benefícios pressupõe que moradores de áreas beneficiadas pelos programas públicos contribuam com valores financeiros arrecadados via medidas fiscais. Esses recursos podem vir de instrumentos como a contribuição de melhorias, paga por aqueles que se beneficiam da valorização de seu imóvel devido ao investimento público e também do IPTU progressivo que, em tese, inibiria a especulação imobiliária dos proprietários que deixam de utilizar seus imóveis aguardando a sua valorização.

Deste modo, o Estado teria condições de recuperar parte dos valores investidos e aplicálos em outros locais da cidade deficitários de investimentos públicos, possibilitando assim conseguir a construção de uma cidade com justiça socioespacial, redução da exclusão social e garantia dos direitos fundamentais dos cidadãos.

Segundo Gaio (2015, p. 31), a intervenção estatal na cidade com instalação de equipamentos públicos em determinadas áreas e a regulação do uso e da ocupação do solo geram aumento do valor do solo urbano. Há o aumento da demanda por imóveis localizados nas regiões onde são instalados os equipamentos públicos e consequente valorização do solo urbano, enquanto no segundo o aumento do valor se dá em função da transformação do solo rural para o urbano.

Em ambos os casos a consequência é uma minoria da população beneficiada pela valorização do solo devido aos investimentos públicos, o que a rigor representa enriquecimento indevido, pois nada foi feito pelos proprietários que justifique a valorização imobiliária. O Estado 
deve, portanto, usar dos mecanismos capazes de distribuir igualmente os benefícios de seu investimento evitando a sua privatização.

Os Municípios têm a função de executar o uso e regulação do solo, organizando o espaço urbano racionalmente, evitar congestionamentos, segregação socioespacial, aumento de terrenos ociosos e impedir que a valorização do imóvel devido aos investimentos públicos fique nas mãos de uma minoria, o que segundo Gaio (2015) não se mostra na prática:

Com base nesses objetivos, compete ao plano diretor municipal - ou, quando este não existir, à lei do perímetro urbano - a tarefa de classificar as propriedades urbanas. Entretanto, esse processo de qualificação urbanística, que consiste na transformação do uso rural para o urbano, implica um acréscimo extraordinário do valor do imóvel, fato este que ocorre sem qualquer esforço por parte do titular do bem [...] Embora alguns gestores públicos argumentem que a municipalidade se favorece com o aumento da arrecadação, o funcionamento desse modelo - que, aliás é típico da América Latina - agrava determinados problemas na medida em que encarece a provisão de serviços públicos cada vez mais distantes dos centros urbanos. Nesse modelo a ampliação da zona urbana em geral não é acompanhada de um imediato adensamento, até porque em outras há ampla oferta de solo para as atividades urbanas (GAIO, 2015, p. 31).

O cotidiano das cidades espelha o que afirma o autor, pois os proprietários sabem que a implantação de equipamentos públicos em determinadas áreas da cidade implicarão na valorização econômica dos imóveis destes locais e deixam seus imóveis ociosos com a finalidade ganhos com a especulação imobiliária, sem nada ter contribuído efetivamente para a sua valorização.

Uma alternativa para se evitar que apenas uma minoria se beneficie é a possibilidade de se utilizar da recuperação das mais valias decorrentes da atuação do Estado. Esse mecanismo tem o condão, em última análise, de dar ao processo urbanístico o caráter igualitário desejado, pois distribui o excedente lucrativo gerado pela ação do Estado no processo de urbanização com o restante da população que não foi beneficiada. Se bem utilizado, o processo das mais-valias dá ao gestor público, ao recuperar parte dos ganhos com o investimento, condições de reinvesti-los em áreas carentes de infraestrutura e segurança como nas zonas de periferias.

A infraestrutura feita pelo Estado é essencial para o aproveitamento urbanístico, mas como o valor econômico da propriedade é determinado pelo seu potencial construtivo, há forte influência do setor imobiliário na elaboração de leis que envolvam o solo, conforme explica Gaio (2015):

Portanto, embora a existência de infraestrutura disponibilizada pelo Poder Público seja essencial ao aproveitamento urbanístico, em última análise o conteúdo econômico da propriedade é preponderantemente determinado pelo seu potencial construtivo, e não pelo solo urbano. Isso explica a forte influência do mercado imobiliário no processo de elaboração de legislações 
como o Estatuto da Cidade e o plano diretor municipal. Registra-se que o Estatuto da Cidade, aprovado em 2001, teve a sua primeira proposta no Anteprojeto de 1982 (Documento, 1982:16-17), o que demonstra o poder de pressão do setor imobiliário. Cita-se ainda o caso do Plano Diretor do município do Rio de Janeiro, de 1992, que adotou o coeficiente único de aproveitamento, mas nunca chegou a ser regulamentado (GAIO, 2015, p. 32).

O Estado, ao privilegiar a participação popular na elaboração de leis para regulação do solo urbano minimizará a influência negativa de grandes econômicos dando a esses instrumentos legislativos o poder de evitar distorções sociais na distribuição dos encargos e benefícios garantindo a efetivação da função social sem o efeito indesejável da privatização dos benefícios com os investimentos públicos.

Para se conseguir a efetivação do usufruto da cidade e a justa distribuição dos encargos e benefícios há que se ter o "sacrifício" de alguns em benefício de outros para que em última instância, se consiga a redução da exclusão social, conforme destaca Gaio (2015):

Embora sejam variadas as motivações para a recuperação da valorização imobiliária - como controlar a especulação ou promover a eficiência do mercado - defende-se que no contexto latino-americano esse processo possua finalidade redistributiva. Com efeito, se a redistributividade consiste "no resultado de uma ação de intervenção do Poder Público que objetive destinar ao conjunto social excedentes considerados coletivos e que são passíveis de apropriação privada", a redistributividade vai além, na medida em que prioriza a repartição desses recursos aos grupos sociais com menos benefícios urbanísticos (GAIO, 2015, p. 33).

Por interferir nos interesses dos proprietários de imóveis e de grandes grupos econômicos e políticos a recuperação da valorização imobiliária, mesmo tendo o caráter social de redistribuição desses ganhos para os grupos sociais menos favorecidos, esse mecanismo é de difícil implantação especialmente no Brasil.

\section{CONSIDERAÇÕES FINAIS}

A implosão da urbanização das cidades induzida pela industrialização representou de um lado a possibilidade do crescimento e desenvolvimento, mas de outro impôs a convivência com os problemas inerentes a esse processo.

O deslocamento do eixo econômico das zonas rurais para locais próximos das fábricas representou mais que o deslocamento do centro de comércio, significou uma grande mudança nas questões culturais. A população de antes, predominantemente rural, inicia a transformação para 
uma população urbana voltada para a busca de melhores condições de vida e acumulação de riqueza obtida com a venda de sua força de trabalho nas fábricas. De certa forma, criou-se uma sociedade individualista.

As cidades mantinham seu caráter corporativo e orgânico de comunidade, herdado da época de aldeia, mas apresentando violentos contrastes entre ricos e pobres, principalmente pela gigantesca exclusão social marcada por uma nova realidade caracterizada pelo valor de uso, sobretudo pela valorização do solo urbano.

A solução para esses problemas passa pela efetiva da participação popular na elaboração e na análise dos resultados das leis de controle do uso e ocupação do solo urbano, efetivo planejamento do crescimento e urbanização das cidades levando em conta os aspectos sociais e ausência de privilégios a determinados grupos de interesse. É indiscutível a existência de grande número de instrumentos à disposição do Estado capazes de produzir uma cidade mais igualitária, mas ao serem efetivados afetarão diretamente interesses individuais e de determinados grupos sociais e, por esse motivo, têm sua aplicação limitada, devido a grande resistência de grupos ligados à especulação imobiliária.

Mesmo diante da resistência na aplicação desses instrumentos, o Estado não pode se furtar a usá-los, pois são instrumentos eficazes na proteção dos direitos coletivos, ainda que para isso tenha que interferir diretamente nos direitos individuais, especialmente no direito de propriedade. Conseguir uma cidade equitativa e socialmente mais justa passa, fundamentalmente, pela ação do Estado na busca da efetivação da função social da propriedade e do solo urbano, mediante a participação popular nas decisões e elaboração das leis, alcançando-se o maior nível possível de justiça socioambiental e socioespacial, o que é representado pelo usufruto equitativo da cidade com a justa distribuição dos encargos e benefícios que advêm do processo de urbanização.

\section{REFERÊNCIAS}

ACSERALD, Henri. Discursos da Sustentabilidade. Revista Brasileira de Estudos Urbanos e Regionais, São Paulo, v. 1, no 01, maio 1999, p. 79-90.

ACSELRAD, Henri; MELLO, Cecília Campello do Amaral; BEZERRA, Gustavo das Neves. O que é justiça ambiental. Rio de Janeiro: Garamond, 2009.

BIZAWU, Kiwonghi; GOMES, Magno Federici. Oil exploitation at Virunga park as a threat to the environment and to endangered animal species. Veredas do Direito, Belo Horizonte, v. 13, n. 27,
p.
11-29,
set./dez.
2016.
Disponível
em: 
<http://www.domhelder.edu.br/revista/index.php/veredas/article/view/897>. Acesso em: 20 jun. 2017.

BRASIL. Constituição da República Federativa do Brasil de 1988. Diário Oficial, Brasília, 05 out. 1988. Disponível em: <www.planalto.gov.br>. Acesso em: 15 out. 2015.

BRASIL. Lei Complementar no 140, de 08 dez. 2011. Fixa normas, nos termos dos incisos III, VI e VII do caput e do parágrafo único do art. 23 da Constituição Federal, para a cooperação entre a União, os Estados, o Distrito Federal e os Municípios nas ações administrativas decorrentes do exercício da competência comum relativas à proteção das paisagens naturais notáveis, à proteção do meio ambiente, ao combate à poluição em qualquer de suas formas e à preservação das florestas, da fauna e da flora; e altera a Lei no 6.938, de 31 de agosto de 1981. Diário Oficial, Brasília, 09 dez. 2011. Disponível em: <http://www.planalto.gov.br/ccivil 03/leis/LCP/Lcp140.html> Acesso em: 25 mar. 2016.

COSTA, Beatriz Souza. Meio ambiente como direito à vida: Brasil, Portugal e Espanha. Rio de Janeiro: Lumen Juris, 2013.

COSTA, Cássia Celina Paula Moreira. A constitucionalização do direito de propriedade privada. Rio de Janeiro: América Jurídica, 2008.

DINIZ, Maria Helena. Curso de direito civil brasileiro. 18. Ed. São Paulo: Saraiva, 2002. V.1. HOBSBAWN, Eric J. Da Revolução industrial inglesa ao Imperialismo. Rio de Janeiro: Forense Universitária, 2011.

GAIO, Daniel. A interpretação do direito de propriedade em face da proteção constitucional do meio ambiente urbano. Rio de Janeiro: Renovar, 2015.

GOITIA, Fernando Chueca. Breve história do urbanismo. Tradução por Emílio Campo Lima. 5. Ed. Lisboa: Presença, 2003

KAPP, Silve. Direito ao espaço cotidiano: moradia e autonomia no plano de uma metrópole. Caderno Metropolitano, São Paulo, v. 14, no 28, p. 463-483, jul./dez. 2012.

KAAP, Silve. Relatório pelo direito fundamental à moradia adequada: estudo do caso de ocupações urbanas em Belo Horizonte e região metropolitana. Programa Cidade e Alteridade: convivência multicultural e justiça rural-urbana da UFMG. <http://www.cidadeealteridade.com.br/wpcontent/uploads/2015/12/relatorio_cidade-e-alteridade-ocupacoes.pdf> Acesso em: 22 abr. 2017

LEFEBVRE, Henri O direito à cidade. São Paulo: Centauro, 2001.

MACHADO, Paulo Afonso Leme. Direito ambiental brasileiro. 21. ed. São Paulo: Malheiros, 2013.

MALUF, Adriana Caldas do Rego Freitas Dabus. Limitações ao direito de propriedade. São Paulo: Atlas, 2010.

MARICATO, Ermínia. As ideias fora do lugar e o lugar fora das ideias: planejamento urbano no Brasil. In: ARANTES, Otília; VAINER, Carlos; MARICATO, Ermínia (Org.). A cidade do pensamento único: desmanchando consensos. Petrópolis: Vozes, 2000. Cap.3, p. 121-192. 
OLIVEIRA, Regis Fernandes. Comentários ao Estatuto da Cidade. 2. ed. São Paulo: Revista dos Tribunais, 2005.

SILVA, Ana Amélia da. Reforma urbana e o direito à cidade. São Paulo: Pólis, 1991.

SILVA, José Afonso da Silva. Direito urbanístico brasileiro. 3. ed. São Paulo: Malheiros, 2000.

TUSHNET, Mark. An essay on rights. Texas Law Review, Texas, v. 62, no 8, p.1363-1412, maio 1984.

Trabalho enviado em 04 de fevereiro de 2019

Aceito em 20 de abril de 2020 